\title{
Medical Causes and Emergency Basic Care In The Place Of Accidents in Road Traffic
}

\author{
Basri Lenjani ${ }^{1 *}$, Nehat Baftiu ${ }^{1 *}$, Nuhi Arsllani ${ }^{1}$, Blerim Krasniqi ${ }^{2}$, Shpresa Makolli ${ }^{2}$, Lirije \\ Beqiri $^{2}$, Aferdita Berisha ${ }^{2}$, Erza Mulaj ${ }^{2}$ and Dardan Lenjani ${ }^{2}$ \\ ${ }^{1}$ Emergency Clinic, Hospital and University Clinical Service of Kosovo, Republic of Kosovo \\ ${ }^{2}$ College of Medical Sciences Resonance, Republic of Kosovo
}

*Corresponding authors: Basri Lenjani, University Clinic Clinical Emergency, Republic of Kosovo

Nehat Baftiu, University Clinical Center of Kosovo, Pristine 10000, Republic of Kosovo

\begin{abstract}
ARTICLE INFO
Received:

Published: May 01, 2020

Citation: Basri L, Nuhi A, Blerim K, Shpresa M, Lirije B, et al., Medical Causes and Emergency Basic Care In The Place Of Accidents in Road Traffic. Biomed J Sci \& Tech Res 27(3)-2020. BJSTR. MS.ID.004496.
\end{abstract}

Keywords: Accidents; Traffic; Disease; Injury; Illness; BLS; Causes; Medical; Emergency; Care

\section{ABSTRACT}

Entry: Road traffic accidents in Kosovo and around the world are taking many lives, causing casualties; injuries, disability, health problem, suffering, economic problems, family problems and death. Medical causes of road traffic accidents are caused; acute illnesses. Chronic, drugs, alcohol and fatigue etc. The Integrated Education Network of the first medical staff education and training is legally obliged to provide medical care at the scene of the accident to ensure and improve the quality of emergency medical care for victims of road traffic accident.

Purpose of work: The main purpose of this retrospective research is to identify the main causes of health problems that affect road traffic accidents, reducing morbidity, disability and mortality by implementing first aid measures at the scene of the accident.

The methodology of work: The research material was taken from the medical documentation of injured in road traffic accidents at the UCCK Emergency Clinic for the period January - December 2019. The research samples were the only injured in road traffic accidents. In the research 5254 cases of road traffic accidents were investigated, the research is of retrospective type, where the medical causes in causing traffic accidents were identified.

Results: According to the January - December 2019 patient numbers, there were 86,690 cases requiring medical assistance and 5254 of them being injured in road traffic accidents or 6.06. Medical causes of traffic accidents, 904 cases or $17.20 \%$ with diabetes, 680 cases or $12.94 \%$ with hypertension, 160 cases or $3.04 \%$ with visual problems and other cases with numbers the smallest of cases. Outbreaks with a nonhealth problem were 3152 cases or $59.99 \%$.

Conclusion: Medical Problems Drugs, alcohol can have a direct impact on causing road traffic accidents to a large extent, which need to be timely intervened. The US Integrated Education Network training and training of first medical staff are legally obliged to provide medical care at the scene of the accident to provide and improve the quality of emergency medical care to victims in the event of a road traffic accident.

\section{Introduction}

Road traffic accidents in Kosovo and around the world are taking many lives, causing casualties; injuries, disability, health problem, suffering, economic, family problems and death. Around 54 million people are injured in road accidents worldwide each year, and about 1.4 million die annually. Middle-income countries have the highest rate of 20 deaths per 100,000 inhabitants. While the death rate in Africa is higher (24.1 per 100,000 populations), the lowest rate is in Europe [1-5]. "To date, 2513 people have died in Kosovo, a worrying figure, but in 2019 (97 dead) or 10 casualties less than the same period last year (107 dead), referring to statistics of the 
Kosovo Police. According to the Kosovo Police, based on statistics on traffic accidents for 2018 that have been injured, there were more than 12,000 injured and 107 dead at the Kosovo roads in 2018. In 2019 , there were a total of 16,222 accidents, up from 15,877 in the same period in 2018. During 2019, however, road traffic accidents increased by 2.17 percent compared to 2018 .

Kosovo Police and EMS distributed leaflets to participants in traffic. The project has also been promoted in social media and media, including lectures and discussions at school institutions. Courses at the Emergency Clinic for the period January-December 2018 for those who required emergency medical care 55.234 / 4750 or $8.59 \%$ of injured road traffic and 32 dead at the Emergency Clinic. And in 2019 those who required emergency medical care 86.690 / 5254 or $6.06 \%$ and died 22 at the Emergency Clinic. The medical causes of traffic accidents can be; acute diseases. Chronic, drowsiness, drug use (Sedative Hypnotics Benzodiazepines), antidepressants. Alcohol, Effects of various drugs, opiates single doses of narcotics, fatigue. The integrated network of EMEA education and training of first medical staff is legally required to provide medical care at the scene of the accident to provide and improve in order to provide an effective medical service [6-8].

\section{Purpose of Work}

The main purpose of this retrospective research is to identify the main causes of health problems that directly affect road traffic accidents, and the measures to be taken to reduce morbidity, disability and mortality by implementing emergency assistance measures. First at the scene of the accident [9].

\section{Methodology of Work}

The research material was taken from the medical records of the injured in traffic accidents at the Clinic Emergency Clinic - UCCK for the period January - December 2019 and January - December 2019. The research samples were 5254 injured in road traffic accidents as well as victims with health reasons, age, gender, and conditions of
BLS delivery on the scene during transport to hospital. Our research is based on these findings to the victims among the drivers of the injured or non-injured vehicle who reported data on the medical conditions and drugs used by the victims prior to the accident. Data were processed in Excel and the frequency and percentage of data was calculated and presented in the form of tables and graphs [1012].

\section{Result}

The research material was obtained from the medical documentation of the injured in road traffic accidents at the UCCK Emergency Clinic for the period January - December 2019. The research samples were the only injured in road traffic accidents with medical causes Table 1 . According to the daily number of patients January - December 2018, emergency medical assistance was requested 55,234 cases per year, of them with injuries in traffic accidents 4750 cases or 8.59\%, while For 2019 January - December were 86,6905254 cases or $6.06 \%$ of those who sought medical assistance and were injured in road traffic accidents. Compared to 2018 the number of injured in road traffic accidents were higher by $8.59 \%$, compared to 2019 the number of injured is lower by $6.06 \%$ or by $2.53 \%$ less (Figures 1-7), Tables 2-7. The highest number of road traffic accident victims were aged 15-29 years with 2900 cases or $55.19 \%$, ages $30-39$ were 1451 cases or $27.81 \%$, and falling from age 40 to $>65$ years. The number of cases without health problems was 3152 cases or $59.99 \%$, while the number of cases with health problems was 2102 cases or $40.01 \%$. For the occurrence of road traffic accidents, the highest number being 904 cases of diabetes or $17.20 \%$, with hypertension 680 cases or $12.94 \%$, with visual problems 160 cases or $3.04 \%$, while other cases had a smaller number of cases. Outbreaks with a non-health problem were 3152 cases or $59.99 \%$. The highest number were with diabetes 904 cases or $17.20 \%$, with hypertension 680 cases or $12.94 \%$, with visual problems 160 cases or $3.04 \%$, with hypertension, hypotension 76 cases or $3.61 \%$, with epilepsy 75 cases or $3.55 \%$ while the other cases had a smaller number of cases.

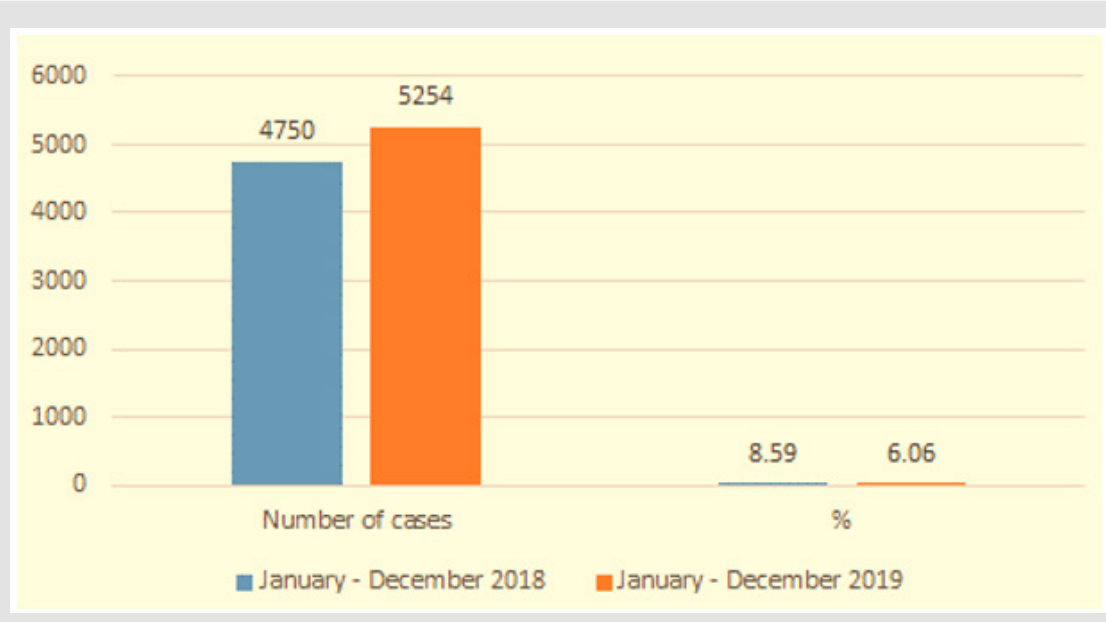

Figure 1: Number of cases by years. 


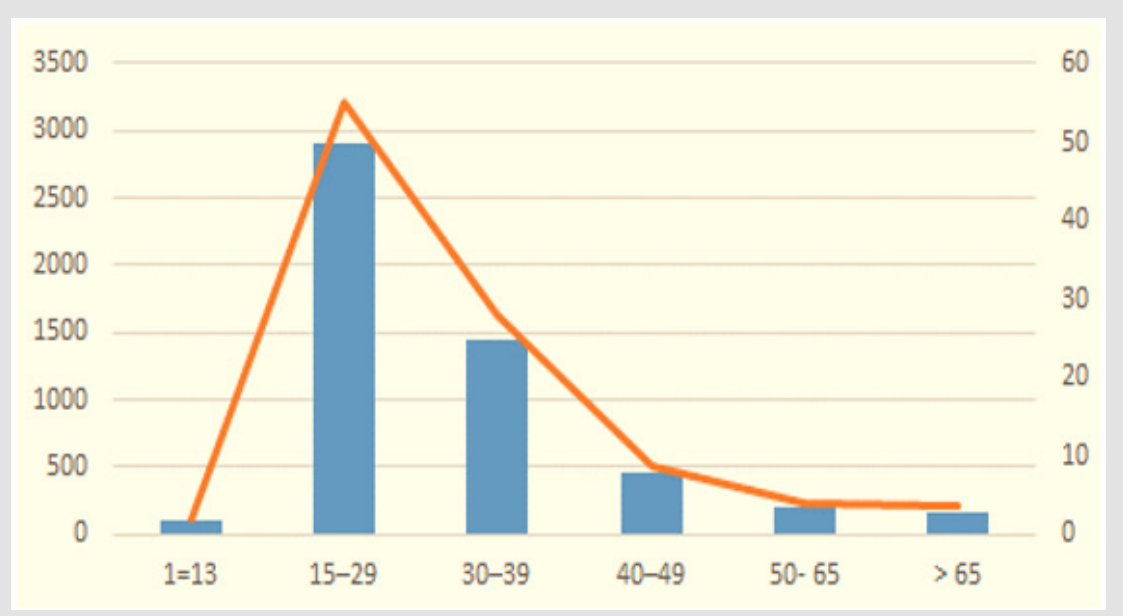

Figure 2: Number of cases by age group.

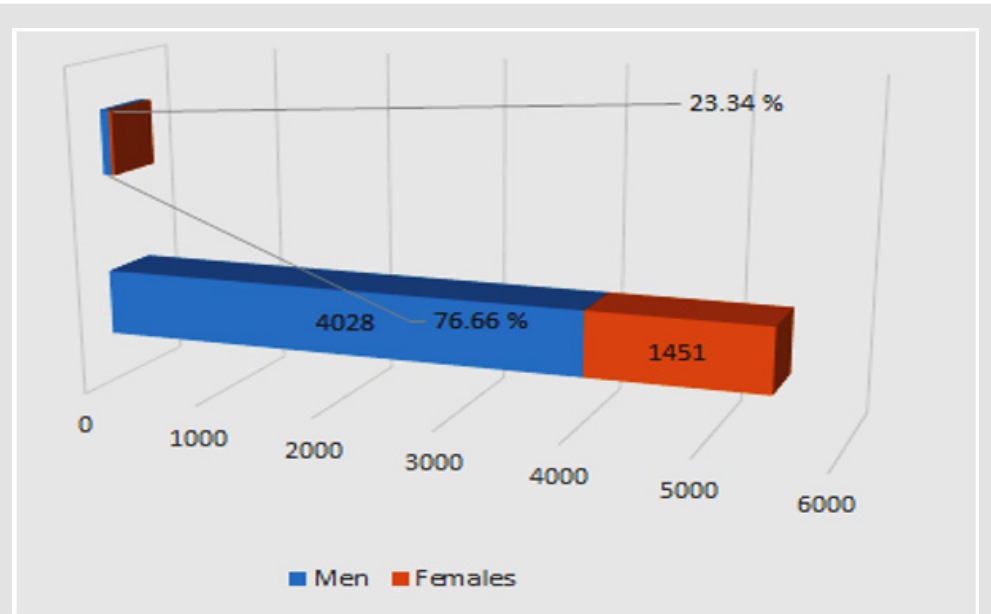

Figure 3: By gender, most of the victims of road traffic accidents were male (76.66\%), and female were $23.34 \%$.

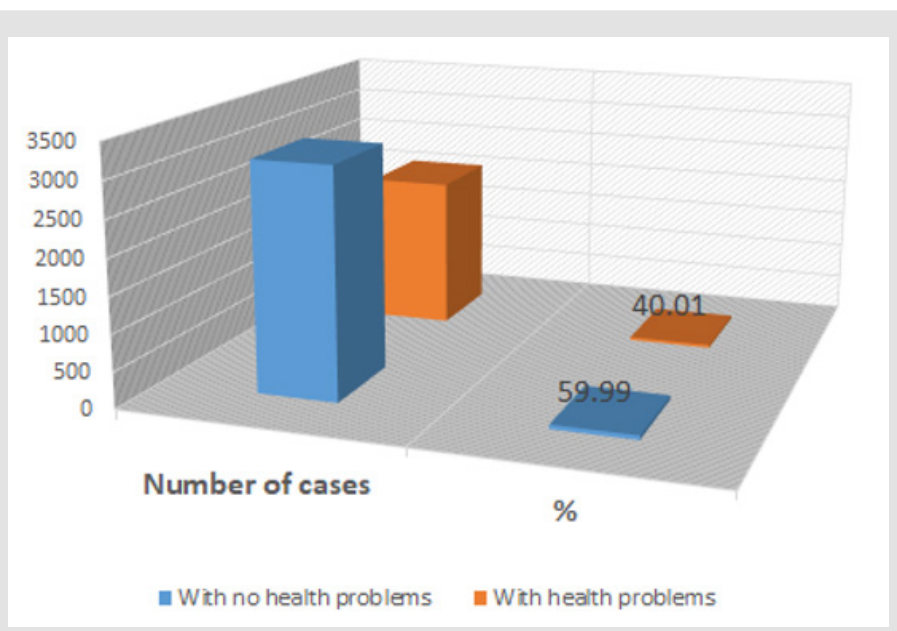

Figure 4: The number of cases gave me major health problems in road traffic accidents. 


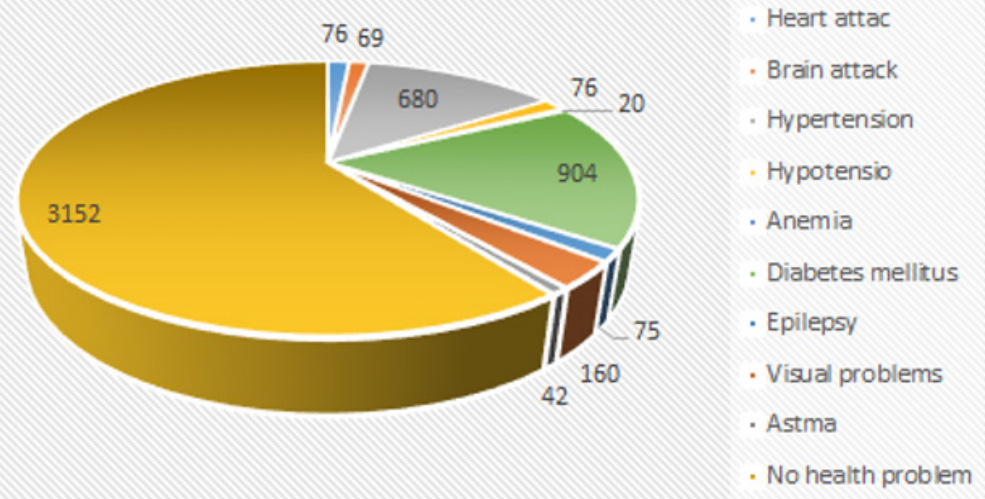

Figure 4: General number of cases and medical causes of occurrence of road traffic accidents Diagram 5. General number of cases and medical causes of occurrence of road traffic accidents.

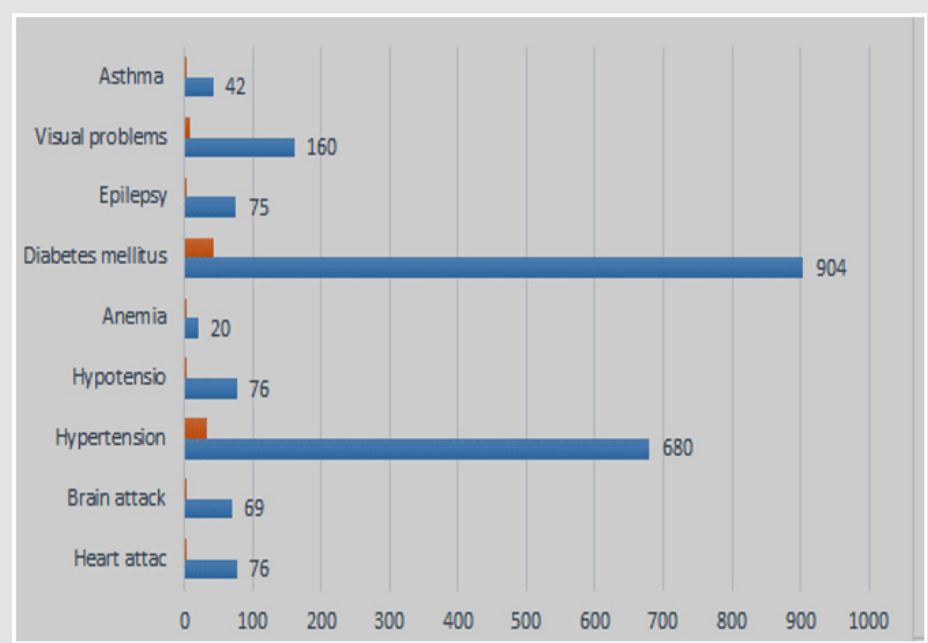

Figure 6: Number of fatalities and medical causes in the occurrence of road traffic accidents.

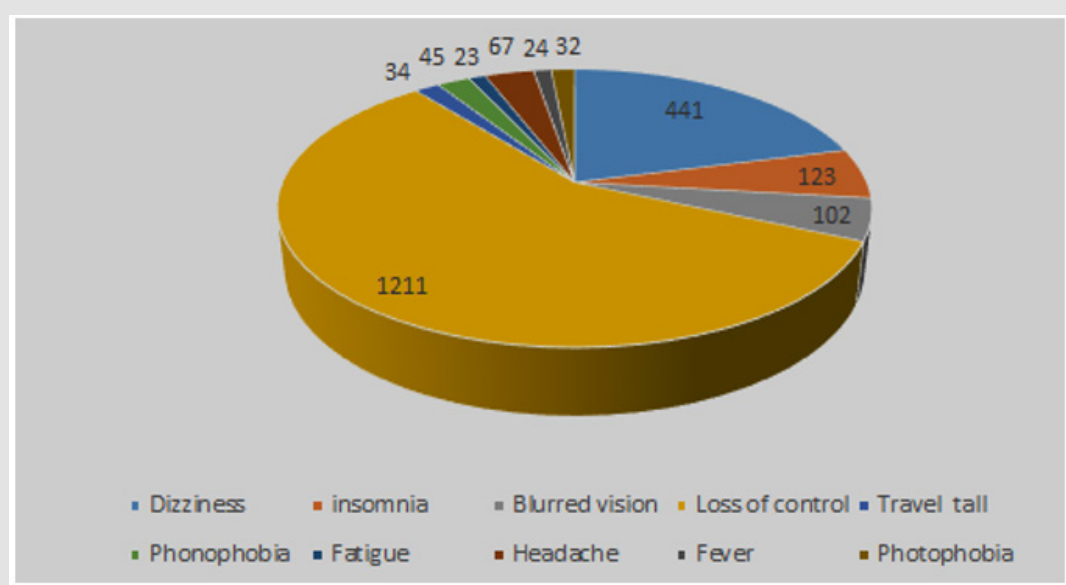

Figure 7: Number of cases based on signs and symptoms reported by car drivers as a result of road traffic accidents, the highest number of injured as the main cause was loss of control by the driver were 1211 cases or $57.61 \%$, with 441 cases or $20.98 \%$ vertigo, 123 cases or $5.71 \%$ fatalities. , with visual impairment were 102 cases or $4.75 \%$, with headache were 67 cases or $3.18 \%$, while other cases were small in number. 
Table 1: Number of cases by year.

\begin{tabular}{|c|c|c|}
\hline Year & Number of cases & \% \\
\hline January - December 2018/55.234 & 4750 & 8.59 \\
\hline January - December 2019/86.690 & 5254 & 6.06 \\
\hline
\end{tabular}

Table 2: Number of cases by age group.

\begin{tabular}{|c|c|c|}
\hline Age & Number of cases & \% \\
\hline $1-13$ & 91 & 5.73 \\
\hline $15-29$ & 2900 & 27.81 \\
\hline $30-39$ & 1451 & 8.5 \\
\hline $40-49$ & 451 & 3.98 \\
\hline $50-65$ & 201 & 3.61 \\
\hline$>65$ & 160 & $100 \%$ \\
\hline
\end{tabular}

Table 3: Number of cases by gender in road traffic accidents.

\begin{tabular}{|c|c|c|}
\hline Gender & Number of cases & \multicolumn{1}{c|}{ \% } \\
\hline Men & 4028 & 23.66 \\
\hline Females & 1451 & $100 \%$ \\
\hline Total & 5254 & \\
\hline
\end{tabular}

Table 4: Number of cases gave me major health problems in road traffic accidents.

\begin{tabular}{|c|c|c|}
\hline Health problems & Number of cases & \% \\
\hline With no health problems & 3152 & 59.99 \\
\hline With health problems & 2102 & 40.01 \\
\hline Total & 5254 & $100 \%$ \\
\hline
\end{tabular}

Table 5: Overall number of cases and medical reasons.

\begin{tabular}{|c|c|c|}
\hline Diseases & Number of cases & \% \\
\hline Heart attack & 76 & 1.44 \\
\hline Brain attack & 69 & 1.31 \\
\hline Hypertension & 680 & 1.94 \\
\hline Hypotension & 76 & 0.38 \\
\hline Anemia & 20 & 17.20 \\
\hline Diabetes mellitus & 904 & 1.42 \\
\hline Epilepsy & 75 & 3.04 \\
\hline Visual problems & 160 & 0.84 \\
\hline Asthma & 42 & 59.99 \\
\hline No health problem & 3152 & $100 \%$ \\
\hline
\end{tabular}

Table 6: Number of casualties and medical causes in causing road traffic accidents.

\begin{tabular}{|c|c|c|}
\hline Diseases & Number of cases & \% \\
\hline Heart attack & 76 & 3.61 \\
\hline Brain attack & 69 & 32.35 \\
\hline Hypertension & 680 & 3.61 \\
\hline Hypotension & 76 & 0.95 \\
\hline Anemia & 20 & 43.01 \\
\hline
\end{tabular}




\begin{tabular}{|c|c|c|}
\hline Epilepsy & 75 & 3.55 \\
\hline Visual problems & 160 & 7.62 \\
\hline Asthma & 42 & 2.02 \\
\hline Total & 2102 & $100 \%$ \\
\hline
\end{tabular}

Table 7: Number of cases based on signs and symptoms reported by car drivers as a result of road traffic accidents.

\begin{tabular}{|c|c|c|}
\hline Signs and symptoms & Number of cases & 20.98 \\
\hline Dizziness & 441 & 5.71 \\
\hline insomnia & 123 & 4.75 \\
\hline Blurred vision & 102 & 57.61 \\
\hline Loss of control & 1211 & 1.61 \\
\hline Travel tall & 34 & 2.14 \\
\hline Photophobia & 45 & 1.09 \\
\hline Fatigue & 23 & 3.18 \\
\hline Headache & 67 & 1.41 \\
\hline Fever & 24 & 1.52 \\
\hline Photophobia & 32 & $100 \%$ \\
\hline
\end{tabular}

\section{Discussion}

The purpose of our research was to recognize and influence medical conditions among victims' leaders. Our research shows to understand the pattern, type and severity of accident injuries and medical conditions among road traffic accident victims. Our research shows an increase in casualties and a decrease in the number of road traffic accidents. Compared to 2018 with 2019 there is a decrease of $2.53 \%$ in the number of road traffic accidents. In Kosovo, the main cause of morbidity and mortality and disability in road traffic is the young age of the population [13-18]. The highest number of road traffic accident victims were aged 15-29 years with 2900 cases or 55.19\%, ages 30-39 were 1451 cases or $27.81 \%$, and falling from age 40 to $>65$ years. Despite the fact that traffic injuries account for only $6.5 \%$ of all road accidents, this represents about $25 \%$ of annual spending in Kosovo which costs in euros. It has been reported that $50 \%$ and $15 \%$ of road accident injuries are related with head injuries, neck, chest, abdomen, pelvis, limbs and spine $[19,20]$.

The number of cases without health problems was 3152 cases or $59.99 \%$, while the number of cases with health problems was 2102 cases or $40.01 \%$.A study conducted in Finland found a higher incidence of road traffic accidents among drivers with a history of arterial hypertension. Of the total number of cases and medical reasons for the occurrence of road traffic accidents, the largest number were those with diabetes 904 cases or $17.20 \%$, with hypertension 680 cases or $12.94 \%$, with visual problems 160 cases or $3.04 \%$, whereas the other cases had a smaller number of cases. Outbreaks with non-health problems were 3152 cases or $59.99 \%$. Number of cases based on signs and symptoms reported by car drivers as a result of road traffic accidents.
The highest number of injured as a main cause was loss of control by the driver were 1211 cases or $57.61 \%$, with vertigo 441 cases or $20.98 \%$, with 123 cases or $5.71 \%$ drowsiness, 102 cases or $4.75 \%$ with vision problems, 67 cases or $3.18 \%$ with headaches, while other cases were small $[21,22]$. The results of our research are consistent with the work of the author Havagiray R. Chitme Impact of Medical Conditions and Medications on Road Traffic Safety, 2018. It is important that the medical causes in causing road traffic accidents should be prevented by taking precautionary measures medicine to the sick suffering from acute chronic illnesses, visual problems, and psychic problems are constantly monitored to avoid serious complications. Despite the fact that traffic injuries account for only $6.5 \%$ of all road accidents, this represents about $25 \%$ of annual spending in Kosovo costing in euros head, neck, chest, abdomen, pelvis, limbs and spine.

\section{Conclusion}

Mild bodily harm cannot be found in any law, so primary categorization at the scene of the accident or on arrival at a health facility later on during treatment or after treatment must be corrected. Injuries to those with mild superficial bodily injury and to a large extent should be treated in an outpatient manner and leave no lasting harmful effects either functionally or aesthetically. Educate and train with BLS courses and advanced trauma healthcare professionals especially pre-hospital and hospital level. Educate and train with basic trauma support courses; police officers, firefighters and communities. Victims with serious bodily harm should be provided medical care only by MS 112 and after stabilization should be urgently referred to the Emergency Clinic for definitive monitoring, diagnosis and treatment. Driving licenses should not be issued without a medical certificate from a strict verification commission [22-24]. 
All drivers of health problems with drugs, the impact of alcohol and drugs all have to pay out of pocket. Driving licenses should not be issued without a medical certificate from a strict verification commission. Emergency health services and Kosovo Police services from accident victims should be involved and such services not covered. Emergency Services and Emergency Response Services can be useful to increase road safety. The Government of Kosovo should make efforts to provide trauma care facilities to Kosovo citizens by establishing many trauma care schemes in Kosovo such as: National Highway Trauma Care Project. National Highways Accident Relief Services Scheme, Incident Management System, and Emergency Medical Service Systems. Project National Highway Traffic Care Project, National Highway Accident Assistance Services Scheme, Incident Management System, Systems Emergency Medical Service Systems.

Incorporate as a subject First aid at lower secondary and upper secondary level and in Universities and Traffic Safety Lower secondary level as a compulsory subject. Organize educational campaigns for traffic participants, schools and communities. Road traffic accidents are a serious social problem requiring immediate action to prevent and implement BLS lifesaving measures which shorten the rescue time to restore vital signs functions, approximately 5 minutes. Because after this period, irreversible changes in life functions occur. Only $10 \%$ of developed European countries have a chance to receive professional medical assistance within 10 minutes of road accident victims. Whereas in Kosovo this time interval is very difficult due to road blockages, lack of ambulances, medical staff as well as education and training skills with first aid courses. The US MSE integrated education and training network of first medical staff is legally required to provide medical care at the scene of the accident to ensure and improve the quality of emergency medical services.

\section{Disclosure}

The authors declared no conflict of interest. No funding was received for this study.

\section{Acknowledgement}

We would like to thank medical staff of Emergency Clinic of the university Clinical center of Kosovo.

\section{References}

1. (2014) Injuries and violence the facts. 7: 14.

2. V Rootle, C Stains, C Brennan, N Haworth, J Ozone-Smith (2003) Suicide and natural deaths in road traffic - review. Monash University Accident Research Centre Report No. 216

3. (2019) Archive emergency clinic University Clinical Center Kosovo.

4. (2017) World Health Organization. Violence and Injury Prevention. Global status report on road safety. WHO, Geneva, Switzerland.
5. (2008) NHTSA. National Motor Vehicle Crash Causation. SAS Analytical User's Manual. Washington, DC: National Highway Traffic Safety Administration.

6. (2005) Dobbs BM Medical Conditions and Driving: A Review of the Literature. DOT HS 809 690. Washington, DC: National Highway Traffic Safety Administration.

7. (2013) World Health Organization. Department of Violence and Injury Prevention and Disability. Global status report on road safety 2013: Supporting a decade of action, Geneva.

8. Senra Moniz C, Alves Serra F, Costa Ferreira R, Vasconcelos C, Machado Saraiva A (2013) Diabetes and driving: evidence and recommendations. Acta Med Port 26(4): 426-442.

9. Brož J, Kriváňová LS, Fedáková Z, Petrosyan L, Kvapil M (2016) Motor vehicle driving and diabetes mellitus - medical aspects. VnitrLek 62(3): 213-235.

10. (2007) Geneva: Global Road Safety Partnership; Last cited on 2012 April 18]. Drinking and Driving: A road safety manual for decision-makers and practitioners.

11. (2008) NHTSA. National Motor Vehicle Crash Causation Survey Report to Congress. DOT HS 811 059. Washington, DC: National Highway Traffic Safety Administration.

12. Gjerde H, Christophersen AS, Normann PT, Mørland J (2011) Toxicological investigations of drivers killed in road traffic accidents in Norway during 2006-2008. Forensic SciInt 212(1-3): 100-106

13. Nnamdi N (2017) Improving Care \& Response in Nigeria. J Emerg Med Serv.

14. Malik FA, Qasab RA, Ali A, Ali S, Zahoor UZ (2016) Pavement Marking as a means of Traffic Control Device Issue. 12,

15. For an Urban Intersection as per Indian Practice, International Journal of Engineering Research \& Technology (IJERT) 5

16. Rudisill TM, Zhu M, Davidov D, Leann Long D, Sambamoorthi U, et al. (2016) Medication use and the risk of motor vehicle collision in West Virginia drivers 65 years of age and older: a case-crossover study. BMC Res Notes. 9: 166.

17. Bhattacharjee M (2017) 33.3\% Decline in road accidents till March: National Centre for Statistics and Information, Royal Omani Polices 2018. Muscat Daily 2018. Satake M. Pharmacist's advice about driving for diabetic patients. Yakugaku Zasshi 137(3): 322-334.

18. Rainio J, Sulander P, Hantula L, Nuutinen J, Karkola K (2007) Diseases and motor vehicle fatalities in Finland in 2001 and 2002. Traffic InjPrev 8(3): 319-326.

19. Ojomoyela R, Ogundipe S, Obinna C (2016) How 6 Ekiti doctors died, survivor recounts; 2016. Vanguard News. 2017.

20. (2008) National Coalition on Health Care [homepage].

21. (2016) Annual Accident Report 2018 - European Commission Road traffic accidents in the Member States of the European Union.

22. Gururaj G, Sateesh VL, Rayan AB, Roy AC, Amarnath, et al. (2008) Bengaluru Injury surveillance collaborators group. National Institute of Mental Health and Neuro Sciences, Publication No. 68.

23. No authors listed. Emergency medical services in Hong Kong. http:// www.bowincars.org/mediawiki-1.6.12/extensions/Fetch.

24. (2019) National Emergency Department Inventories. Emergency Medical Network. 
ISSN: 2574-1241

DOI: $10.26717 /$ BJSTR.2020.27.004496

Basri Lenjani. Biomed J Sci \& Tech Res

(C) (i) This work is licensed under Creative BY Commons Attribution 4.0 License

Submission Link: https://biomedres.us/submit-manuscript.php

$\begin{array}{ll}\text { BIOMEDICAL } & \text { Assets of Publishing with us } \\ \text { RESEARCHES } & \text { - Global archiving of articles } \\ \text { - Immediate, unrestricted online access }\end{array}$

